\title{
Reappraisal of the ratio of disc to macula/disc diameter in optic nerve hypoplasia
}

\author{
Sabah M Zeki, John Dudgeon, Gordon N Dutton
}

\begin{abstract}
The ratio of disc to macula/disc diameter is characteristically increased in eyes with optic nerve hypoplasia. We present the largest reported series of patients with a definitive diagnosis of optic nerve hypoplasia for whom this ratio has been determined. All measurements were made by an independent masked observer. Our results are in accordance with previous reports. A ratio of 2.94 provides a one-tailed upper population limit of $95 \%$. An attempt has been made to correlate optic disc size and visual acuity. In $75 \%$ of bilateral cases the eye with the relatively smaller optic disc was found to have a better Snellen visual acuity than the fellow eye. This suggests that additional pathogenic mechanism(s) may have determined the eventual visual outcome in such eyes. Such mechanisms include macular hypoplasia, high refractive error, refractive amblyopia, central scotoma, and optic atrophy.
\end{abstract}

Underdevelopment of one or both optic nerves is a common anomaly. ${ }^{1}$ The aetiology is unknown. Optic nerve hypoplasia $(\mathrm{ONH})$ is a diagnosis which should be considered in any person with poor vision for which there is no immediately apparent explanation. Although the small optic disc of $\mathrm{ONH}$ is easily detected in severe cases, more subtle forms of the disorder may present more difficulty. The differential diagnosis includes the apparently small optic nerve head of hypermetropia. Subtle forms of the disorder may be difficult to distinguish from normal appearances. Red-free fundus photography can aid in this differentiation by detecting evidence of nerve fibre layer defects which correspond with that of the pattern of visual field loss. ${ }^{2}$ However, many cases of ONH do not show such focal defects and are manifest solely as a uniformly thin nerve fibre layer within affected areas, which makes the condition more difficult to define than focal defects. ${ }^{3}$

Franceschetti and Bock ${ }^{4}$ measured the optic disc diameter by means of focal illumination of the fundus, using contact lens biomicroscopy and a micrometer scale. Estimation of the size of the optic disc by comparing the slit beam width on the Hagg-Streit 900 slit-lamp with the optic disc diameter on contact lens biomicroscopy has also been advocated. ${ }^{5}$ These relative measurements are useful in comparing the diameter of the optic disc relative to the slit-lamp beam or the scale, because their magnification when projected on the optic disc is assumed to be the same as the magnification of the optic disc, as the slit beam and microscope optics are parfocal and both pass through the optical system of the eye.
Other methods which have been described include comparison of the size of the optic disc with the size of the whole area of the fundus as seen in the standard fundus photograph, ${ }^{6}$ measurement with a scale over the frontal lens during indirect ophthalmoscopy, ${ }^{7}$ direct measurements of the orbital part of the optic nerve by CT scanning, ${ }^{8}$ A-scan ultrasonography, ${ }^{8}$ and B-scan ultrasonography. ${ }^{9}$

Variations in the size of the eye with concomitant differences in dioptric power even in emmetropic eyes render absolute measurement of intraocular structures difficult. ${ }^{1011}$ Interference fringes provide a means of accurate measurement ${ }^{12}$ but necessitate sophisticated equipment and a co-operative patient. The alternative is to make relative measurements from fundus photographs. The apparent size of the optic disc in fundus photographs is influenced by several factors, including the axial length, corneal curvature, and the shape of the fundus, ${ }^{13}$ and by refractive errors and optical aberrations, but because all photographed structures are equally influenced by anatomical and refractive variation such ratios are informative. Thus comparison of the optic disc diameter (DD) with the distance between the disc and macula (D-M) provides a useful index (D-M/DD ratio) of optic nerve head size. This assumes that the paired parameters normally bear a constant relation to each other. $\mathrm{ONH}$ has been said to be characterised by a ratio greater than $3: 1 .^{14-16}$

We have carried out a detailed study on patients with $\mathrm{ONH}^{17}{ }^{18}$ and report our findings on the sensitivity of this technique employing the $D-M / D D$ ratio on a cohort of patients with this condition.

\section{Patients and methods}

\section{PATIENTS}

The sources of patients were as follows: (1) The in-patient disease index of the Royal Hospital for Sick Children (RHSC), Glasgow; (2) the RHSC outpatient department diagnostic index maintained by the consultant staff; (3) Aberdeen Royal Infirmary, Scotland (with permission of the head of the department); (4) newly presenting cases (two patients with $\mathrm{ONH}$ and two with segmental ONH).

The patients thus identified were requested to attend for review. The unaided and corrected visual acuities were tested, and cycloplegic retinoscopy (half an hour after instilling 1\% cyclopentolate eyedrops) was performed. The visual acuities were retested with correction whenever required. The $\mathrm{D}-\mathrm{M} / \mathrm{DD}$ ratio was identified according to the protocol outlined below. All eyes with non-segmental ONH had 
Figure 1 The appearance of the optic disc in $\mathrm{ONH}$ The 'double ring' sign is demonstrated. An inner ring represents the borders of the optic disc (arrow), and an outer ring represents the outer border of the glial tissue.

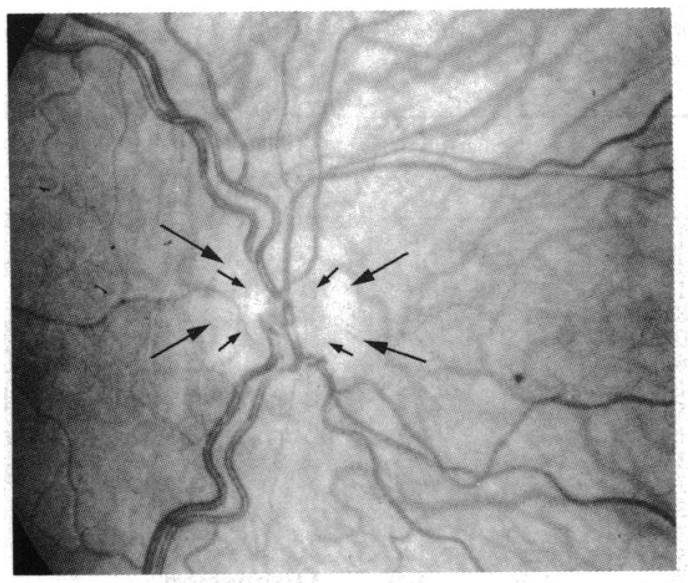

subnormal uncorrected visual acuities. The 'double ring' sign, which is well described in the ophthalmic literature,${ }^{819}{ }^{20}$ was present in all eyes (Fig 1), except in the two eyes of patient 6. However, this patient had constriction of the visual fields to $5^{\circ}$ from fixation, mental retardation, cerebral palsy, and hypothalamic dysfunction.

\section{CONTROL SUBJECTS}

Eighteen normal school children from a local school were tested after permission from the health authorities had been sought and consent of the parents had been obtained. All 18 children attended the clinic and together with three adult volunteers underwent visual acuity assessment, retinoscopy, and fundus photography according to the same protocol as the patients. The ages of the normal subjects ranged from 4 to 35 years (median 9, mean 10.47).

\section{FUNDUS PHOTOGRAPHY}

All patients and control subjects underwent bilateral fundus photography. One drop of $1 \%$ cyclopentolate eyedrops was used to dilate the pupils. Both colour and red-free photographs were taken in order to facilitate identification of the optic disc boundaries and foveal position in difficult cases. Two colour (64 ASA Kodak Ektachrome) and two red-free colour fundus photographs (400 ASA Kodak Ektachrome) were taken with the same fundus camera (Canon CF-60 Z) at the $40^{\circ}$ setting, and the clearest photographs were evaluated. In two cases (patients 6 and 20) $35^{\circ}$ red-free fundus photography had been taken in Aberdeen Royal Infirmary (this does not, however, affect the determination of the $D-M / D D$ ratio from these fundus photographs - see below).

\section{IMAGE ANALYSIS}

Fundus photographs were assessed by the VIDS $\mathrm{V}$ image analysis system (Analytic Measuring Systems Ltd). In every case the average disc diameter was calculated by adding the vertical and transverse disc diameters and then dividing by 2 . The distance from the temporal margin of the optic disc to the fovea was measured from each photograph for both groups of subjects. Half the average diameter of the optic disc was added to this distance to obtain the 'disc-macula distance'. The disc-macula/disc diameter (D-M/ DD) ratio was calculated for all patients and normal subjects. The same calibration technique was used for all the photographs studied. All the readings were taken and analysed separately by a masked independent observer (GND). The slides of the patients and of the normal control subjects had been mixed at random before they were analysed.

\section{VISUAL ACUITY}

The Snellen chart was used to test both the uncorrected and corrected visual acuities at a distance of 6 metres. The luminance of the Snellen test type was measured by a Solex SL 100 Lux meter; the mean screen luminance of six readings was $2900 \mathrm{asb}$. When young age or mental retardation resulted in inability to read the Snellen characters, the identity of the letters was sought by asking the subject to point to corresponding letters on a hand held SheridanGardiner test form.
Table 1 Relationship of the visual acuity to the $D-M / D D$ ratio in the patient group

\begin{tabular}{|c|c|c|c|c|c|c|c|c|}
\hline \multirow[b]{2}{*}{ Patient } & \multirow[b]{2}{*}{ Age } & \multirow[b]{2}{*}{ Sex } & \multicolumn{2}{|c|}{ Unaided VA } & \multicolumn{2}{|c|}{ Aided VA } & \multicolumn{2}{|c|}{$D-M / D D$ ratio } \\
\hline & & & $O D$ & OS & $O D$ & OS & $O D$ & $O S$ \\
\hline $\begin{array}{r}1 \\
2 \\
3 \\
4 \\
5 \\
6 \\
7 \\
8 \\
9 \\
10 \\
11 \\
12 \\
13 \\
14 \\
15 \\
16 \\
17 \\
18 \\
19 \\
20 \\
217 \\
227\end{array}$ & $\begin{array}{r}4 \\
4 \\
8 \\
17 \\
21 \\
19 \\
11 \\
3 \\
2 \\
15 \\
16 \\
6 \\
14 \\
7 \\
7 \\
26 \\
4 \\
19 \\
4 \\
43 \\
9 \\
22\end{array}$ & 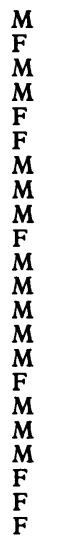 & $\begin{array}{l}0 \cdot 5 / 60 \\
6 / 18 \\
1 \cdot 5 / 60 \\
6 / 60 \\
\star \\
6 / 60 \\
3 / 60 \\
\star \\
1 / 60 \\
6 / 36 \\
6 / 9 \\
3 / 60 \\
6 / 60 \\
6 / 36 \\
3 / 60 \\
6 / 7 \cdot 5 \\
6 / 60 \\
6 / 12 \\
6 / 12 \\
\dagger \\
6 / 6 \\
6 / 7 \cdot 5\end{array}$ & $\begin{array}{l}3 / 60 \\
6 / 12 \\
6 / 36 \\
6 / 60 \\
\star \\
5 / 60 \\
6 / 60 \\
\star \\
6 / 9 \\
6 / 18 \\
6 / 24 \\
6 / 60 \\
6 / 36 \\
6 / 60 \\
1 \cdot 5 / 60 \\
6 / 7 \cdot 5 \\
6 / 36 \\
6 / 7 \cdot 5 \\
6 / 18 \\
6 / 18 \\
6 / 6 \dagger \\
6 / 6 \dagger\end{array}$ & $\begin{array}{l}0 \cdot 5 / 60 \\
6 / 18 \\
1 \cdot 5 / 60 \\
6 / 60 \\
\star \\
6 / 24 \\
6 / 60 \\
\star \\
1 / 60 \\
6 / 18 \\
6 / 7 \cdot 5 \\
3 / 60 \\
6 / 60 \\
6 / 36 \\
3 / 60 \\
6 / 6 \\
6 / 60 \\
6 / 7 \cdot 5 \\
6 / 12 \\
+ \\
6 / 6 \\
6 / 6\end{array}$ & $\begin{array}{l}3 / 60 \\
6 / 12 \\
6 / 36 \\
6 / 24 \\
\star \\
6 / 18 \\
6 / 36 \\
\star \\
6 / 9 \\
6 / 12 \\
6 / 12 \\
6 / 60 \\
6 / 36 \\
6 / 60 \\
1 \cdot 5 / 60 \\
6 / 6 \\
6 / 36 \\
6 / 6 \\
6 / 12 \\
6 / 12 \\
6 / 6 \dagger \\
6 / 6 \dagger\end{array}$ & $\begin{array}{l}3 \cdot 23 \\
3.04 \\
6.08 \\
3 \cdot 26 \\
3.44 \\
4.08 \\
? \\
3.45 \\
3 \cdot 87 \\
? \\
2 \cdot 80 \\
3 \cdot 32 \\
2 \cdot 91 \\
? \\
? \\
2 \cdot 68 \\
3.44 \\
3.22 \\
3.47 \\
? \\
3.33 \\
3.27\end{array}$ & $\begin{array}{l}4 \cdot 00 \\
? \\
4 \cdot 60 \\
3 \cdot 61 \\
3 \cdot 85 \\
4 \cdot 24 \\
3 \cdot 67 \\
3 \cdot 53 \\
? \\
4 \cdot 40 \\
? \\
3 \cdot 67 \\
3 \cdot 58 \\
3 \cdot 48 \\
3 \cdot 26 \\
3 \cdot 14 \\
3 \cdot 28 \\
3 \cdot 32 \\
3 \cdot 10 \\
3 \cdot 06 \\
2 \cdot 72 \\
2 \cdot 71\end{array}$ \\
\hline
\end{tabular}

$\star$ Blind eyes. †Eyes deemed to have no ONH. $\ddagger$ Patients with unilateral right segmental ONH. $?=$ Not available. $\mathrm{VA}=$ visual acuity.

\section{Results}

Fundus photographs were taken for both eyes of 21 normal subjects by the same protocol. It was possible to determine the D-M/DD ratio for 40 eyes of 21 normal subjects. It was also possible to perform fundus photography in 41 eyes of 23 patients, including two patients with segmental ONH. However, in two eyes the quality of the photographs was poor, in two other eyes the fovea was not included in the fundus photographs, and in a further three eyes the fovea could not be located. Therefore measurements could be made to provide the $D-M / D D$ ratio for 34 eyes of 22 patients (Table 1 ).

The mean D-M/DD ratio for the two eyes was taken as the datum value for a subject unless only one eye had been assessed, in which case the value for that eye was taken. The rationale for this type of analysis has been described previously. ${ }^{21} 22$

The mean D-M/DD ratio for the normal 
Table 2 Refractive errors of patients (reproduced with permission from the British fournal of Ophthalmology 1990; 74: 297-9)

\begin{tabular}{lcclll}
\hline & \multicolumn{2}{l}{ TSP } & & \multicolumn{2}{l}{ Astigmatism } \\
\cline { 2 - 3 } \cline { 5 - 6 } Patients & OD & OS & & OD & OS \\
\hline 1 & 1.62 & 1.12 & & 0.25 & 0.75 \\
2 & 3.12 & 3.12 & & 0.25 & 0.25 \\
3 & 2.00 & 2.12 & & 0.5 & 1.75 \\
4 & -2.25 & -0.87 & & 6 & 3.25 \\
5 & 0.12 & 0.00 & & 1.75 & 1.5 \\
6 & 1.37 & 2.62 & & 0.75 & 2.75 \\
7 & 1.25 & 1.12 & & 4.00 & 4.25 \\
8 & 1.62 & 0.5 & & 1.25 & 1.5 \\
9 & 2.25 & 2.12 & & 0.5 & 0.25 \\
10 & -1.37 & -1.37 & & 4.25 & 4.25 \\
11 & 1.25 & 0.75 & & 0.5 & 0.5 \\
12 & 1.12 & 2.37 & & 2.75 & 2.25 \\
13 & 0.5 & 0.37 & & 2.5 & 2.25 \\
14 & 1.5 & 2.5 & & 1.5 & 2.5 \\
15 & 0.25 & -2.25 & & 1.25 & 2.25 \\
16 & 1.75 & 1.75 & & 0.5 & 0.5 \\
17 & 4.5 & 5.00 & 0.5 & 1.00 \\
18 & 1.5 & 2.37 & 0.5 & 0.25 \\
19 & 2.00 & 2.62 & 1.00 & 1.75 \\
20 & $\dagger$ & 0.5 & $\dagger$ & 0.5 \\
$21 \star \ddagger$ & 3.00 & $3.00 \dagger$ & 0.00 & 0.00 \\
$22^{\star} \ddagger$ & 1.75 & $1.75 \dagger$ & 0.00 & 0.00 \\
\hline
\end{tabular}

${ }^{\star}$ In dioptres. $†$ Eyes deemed to have no ONH.

$\ddagger$ Patients with segmental $\mathrm{ONH}$. TSP $=$ total spherical power

group was $2 \cdot 62$. The mean ratio for the patient group was 3.57. As the data were found to be not normally distributed, an upper limit for the normal range was estimated by direct calculation of percentiles. ${ }^{23}$ In view of the relatively small number of control subjects the most extreme limit which could be calculated was the $95 \%$ onetailed upper population limit, which was $2 \cdot 94$. For only one patient (No. 11, who had bilateral $\mathrm{ONH}$, but for whom only the right eye could be photographed) was the D-M/DD within this $95 \%$ limit for normal subjects; his D-M/DD ratio was $2 \cdot 80$. However, this patient showed the double ring sign in both eyes, and his corrected visual acuities were OD 6/7.5 and OS 6/12.

We looked at the visual acuity of the better eye in 12 patients with bilateral $\mathrm{ONH}$ for whom fundus photographs were available (blind eyes and eyes with segmental $\mathrm{ONH}$ were excluded) (Table 1). The visual acuities were compared with the D-M/DD ratios. No significant correlation was found (Pearson correlation coefficient, $p>0 \cdot 1)$. Furthermore, in the eight patients with bilateral ONH for whom the D-M/DD ratio was calculated for both eyes, and for whom the visual acuities of the two eyes were different (patients 1 , $3,4,6,12,13,17,18)$ six patients $(75 \%$ were identified in whom the eye with the better visual acuity had a relatively larger $\mathrm{D}-\mathrm{M} / \mathrm{DD}$ ratio than the worse eye (Table 1).

It is of interest that in 12 of 15 patients (80\%) in this series, with bilateral $\mathrm{ONH}$ and asymmetrical corrected visual acuities, the left eye was the better eye. It is also noteworthy that for 10 out of $12(83 \%)$ of the patients with bilateral $\mathrm{ONH}$ for whom the $\mathrm{D}-\mathrm{M} / \mathrm{DD}$ ratio could be determined for both eyes there was more astigmatism in the eye with the smaller D-M/DD ratio (the eye with the relatively larger optic disc) (Table 2). In only one patient was the degree of astigmatism less in the eye with the smaller ratio, and in one patient there was an equal degree of astigmatism of 0.5 dioptre in both eyes. This has been reported in detail elsewhere. ${ }^{17}$

Six patients $(4,6,7,10,12,13)$ had bilateral asymmetrical $\mathrm{ONH}$ with a significant refractive error in the eye which had the smaller D-M/DD ratio. The visual acuities both with and without correction were the same in the eye with the better visual acuity for two of these patients (12 and 13). Visual acuities were improved with correction by more than one Snellen line in only two patients.

As for the two patients with segmental ONH, although the D-M/DD ratios for the affected eyes were significantly higher than for the normal fellow eyes, there was no impairment of visual acuity and no associated refractive error.

\section{Discussion}

The D-M/DD ratio is the ratio of the horizontal distance between the centre of the optic disc and the macula to the mean diameter of the optic disc, as evaluated from fundus photographs. This study presents the largest series of patients with $\mathrm{ONH}$ in whom this ratio has been measured. The second largest series comprised 19 eyes of 11 patients with ONH. ${ }^{15}$

The $95 \%$ one-tailed upper population limit of the $\mathrm{D}-\mathrm{M} / \mathrm{DD}$ ratio for the normal group in this study was $2 \cdot 94$. This indicates that in practice a ratio of 3 or more provides reliable supportive evidence for the diagnosis of $\mathrm{ONH}$, and accords with previous reports. ${ }^{14-16}$ Awan $^{14}$ selected the horizontal meridian only as an index for the disc diameter. Both Awan ${ }^{14}$ and Wakakura and Alvarez ${ }^{15}$ added half the transverse diameter of the optic disc to the distance between the fovea centralis and the temporal margin of the optic disc in order to calculate the disc-macula distance.

The pupils of only one patient (who was blind; no. 5) did not react to light. This absence of the pupillary light reaction indicates severe involvement of the light sensitive ganglion cells and the 'pupillary' fibres in the optic nerve as well as all the other ganglion cells, as this patient had no light perception in either eye.

The small size of the optic disc must be associated with the visual deficit in these patients. The following findings that indicate that additional factor(s) must contribute to the eventual visual outcome: (1) the visual acuities and the D-M/DD ratios were not significantly correlated in patients with bilateral $\mathrm{ONH}$; (2) $75 \%$ of patients with assymmetrical bilateral ONH had a better visual acuity in the eye with the relatively larger D-M/DD ratio. Such factors may include the following.

Macular hypoplasia. In three eyes for which the photographs had been correctly exposed the position of the fovea could not be discerned in any of the fundus photographs, which therefore excluded them from further study. The visual acuities in these three eyes were hand movement in two and counting fingers in one. This suggests a degree of macular hypoplasia in these eyes, which may comprise features other than isolated absence of ganglion cells in the macula and their nerve fibres. Macular hypoplasia has not hitherto been described in association with ONH. However, histopathological study would be required to validate this hypothesis. In the two histopathological reports for patients blind with 
$\mathrm{ONH}$ total absence of the ganglion cells and the nerve fibre layer has been documented in the affected retinae, but no comments were made on macular morphology. ${ }^{24} 25$

Central scotoma. It was not possible to assess the visual fields in any of the patients who had poor corrected visual acuities. For one patient (no. 4) visuscopy indicated that an area temporal to the macula was employed for fixation by each eye. Both of these eyes had uncorrectable visual acuities despite high refractive errors. It is likely that in this patient eccentric fixation may have been caused by large central scotomata, perhaps due to underdevelopment of ganglion cells of the macula.

Refractive errors and refractive amblyopia. Refractive errors have recently been reported in association with $\mathrm{ONH} .{ }^{17}$ In patients. 7 and 10 there were high refractive errors in the better eyes, but the better eye of each of these patients improved by only one Snellen line by correction. An element of refractive amblyopia may therefore have contributed to impaired visual function in these two patients.

Optic atrophy. Optic atrophy and $\mathrm{ONH}$ are both manifestations of an 'insult' to the developing optic nerve. Therefore it is possible that the pale colour of the optic disc commonly seen in $\mathrm{ONH}$ is not due to a relative increase in the proportion of glial tissue (which is believed not to be affected in $\mathrm{ONH}$ ), but is due to an absolute increase of the glial tissue and diminished vasculature in these optic nerves due to concomitant optic atrophy.

In conclusion, we recommend application of the $\mathrm{D}-\mathrm{M} / \mathrm{DD}$ ratio to assist in confirming the diagnosis of ONH. Simple measurements from fundus photographs are easy to carry out. In a child with bilateral ONH conclusions on the visual potential for an eye should not be drawn from the appearance of the optic disc alone. The diagnosis of $\mathrm{ONH}$ necessitates careful retinoscopy not only to exclude hypermetropia, but also to exclude associated astigmatic refractive errors in such patients, so that their visual development may be optimised.

Further research is required to explain the observation that several patients with ONH had no significant improvement in their visual acuities despite correction of high refractive errors. Further research is also required into concomitant mechanisms, other than the optic nerve size, which may impair the eventual visual outcome in some patients with bilateral $\mathrm{ONH}$. We thank Professor John V Forrester and Dr J Stanley Cant for
allowing us access to patients under their care. We thank Dr Donald Allan for his help with the statistical analyses. Thanks are also due to Mrs Anne Currie for helping with the photography. also due to Mrs Anne Currie for helping with the photography.
The image analysis equipment was purchased with SHHD grant The image analysis equip
NO K/MRS/50/C1294.

1 Hoyt CS. Optic nerve hypoplasia: changing perspective. Aust NZ 7 Ophthalmol 1986; 14: 325-31.

2 Frisen L, Holmegaard L. Spectrum of optic nerve hypoplasia. Brf Ophthalmol 1978; 62: 7-15.

3 Hoyt WF, Frisen L, Newman NN. Funduscopy of nerve fibre layer defects in glaucoma. Invest Ophthalmol 1973; 12: 814 29.

4 Franceschetti A, Bock RH. Megalopapilla: a new congenital anomaly. Am f Ophthalmol 1950; 33: 227-34.

5 Beuchat L, Safran AB. Optic nerve hypoplasia: papillary diameter and clinical correlation. $f$ Clin Neuro Ophthalmol 1985; 5: 249-53.

6 Taylor D. Congenital tumours of the anterior visual system with dysplasia of the optic discs. Br $\mathcal{F}$ Ophthalmol 1982; 66: w55-63.

7 Spinelli F. Mikrometrie des Augenhinter-grundes, Bestimmung und sklerale Lokalisation von Netzhautpunkten, ausgefuhrt mit speziellen Zusatzteilen am vereinfachten Gullstrandschen Ophthalmoskop. Klin Monatsbl Augenheilk 1934; 92: 93-107.

8 Acers TE. Optic nerve hypoplasia: septo-optic-pituitary dysplasia syndrome. Trans Am Ophthalmol Soc 1981; 79: 42557.

9 Boynton JR, Pheasant TR, Levine MR. Hypoplastic optic nerves studied with B-scan ultrasonography and axial tomography of the optic canals. Can $\mathcal{F}$ Ophthalmol 1975; 10: 47381 .

10 Sorsby A. Modern ophthalmology. Washington, DC: Butterworth, 1964; 3: 3 .

11 Jonas JB, Gusek GC, Guggenmoos-Holzmann, Naumann GOH. Variability of the real dimensions of normal human optic discs. Graefes Arch Clin Exp Ophthalmol 1988; 226: optic disca.

12 Kennedy SJ, Schwartz B, Takamoto T, Eu JKT. Interference fringe scale for absolute ocular fundus measurement. Invest Ophthalmol Vis Sci 1983; 24: 169-74.

13 Littmann $\mathrm{H}$. Determination of the real size of an object on the fundus of the living eye. Klin Montasbl Augenheilkd 1982; 180: 286-9.

14 Awan KJ. Ganglionic neuroretinal aplasia and hypoplasia: aplasia and hypoplasia of optic nerve. Ann Ophthalmol 1976; 8: 1193-202.

15 Wakakura M, Alvarez E. A simple clinical method of assessing patients with optic nerve hypoplasia. The disc-macula patients with optic nerve hypoplasia. The disc-macula distance to 65 : $612-7$.

16 Alvarez E, Wakakura M, Khan Z, Dutton GN. The discmacula distance to disc diameter ratio: a new test for confirming optic nerve hypoplasia in young children. $\mathcal{f}$ Pediatr Ophthalmol Strabismus 1988; 25: 151-4

17 Zeki SM. Optic nerve hypoplasia and astigmatism: a new association. BrF Ophthalmol 1990; 74: 297-9.

18 Hollman AS, Straiton JS, Zeki SM. Intracranial abnormalities in patients with optic nerve hypoplasia. Pediatr Radiol 1990 20: 384 .

19 Mosier MA, Lieberman MF, Green WR, Knox DL. Hypoplasia of the optic nerve. Arch Ophthalmol 1978; 96: 143742.

20 Lambert SR, Hoyt CS, Narahara MH. Optic nerve hypoplasia. Surv Ophthalmol 1987; 32: 1-9.

21 Ray WA, O'Day DM. Statistical analysis of multieye data in ophthalmic research. Invest Ophthalmol Vis Sci 1985; 26: ophthalmic

22 Newcombe RG, Duff GR. Eyes or patients? Traps for the unwary in the statistical analysis of ophthalmological studies. BrF Ophthalmol 1987; 71: 645-6.

23 Bland M. An introduction to medical statistics. Oxford: Oxford University Press, 1987: 285-8.

24 Kreibig W. Über Aplasie and Hypoplasie der papilla nerv optici. Klin Monatsbl Augenheilkd 1959; 135: 212-23.

25 Mosier MA, Lieberman MF, Green WR, Knox DL. Hypoplasia of the optic nerve. Arch Ophthalmol 1978; 96: 1437- 